\title{
1. Arts spaces, new urban landscapes and global cultural cities
}

This book is about cities 'going global' and the cultural and urban strategies adopted towards that end. While global cities have most commonly been characterized as key sites of capital transactions and accumulation, as command centres of intensive and extensive economic activity and as networked nodes, with multiple and recurrent global flows of people, goods, services, ideas and images, the quest for global city status also increasingly rests on the production and consumption of culture and the arts, so that global cities might well be characterized as 'global cultural cities'. This book examines the ambitions and projects relating to arts, culture and creative production undertaken in five major cities in Asia, namely, Beijing, Shanghai, Hong Kong, Taipei and Singapore; it analyses the similarities and differences in their strategies, and their relative successes and failures. In so doing, we hope to contribute to a range of literatures on global cities, urban imaging, urban boosterism, urban rejuvenation, cultural mega-projects and cultural/creative industries and clusters.

This introductory chapter provides the theoretical context and larger empirical backdrop within which subsequent individual chapters are to be read. In particular, we introduce the reader to the literature on global cities, highlighting the ways in which global cities have typically been characterized and the manner in which competition among global cities has been studied. We then elaborate on the ways in which new urban landscapes are very much a part of many urban boosterism strategies, and we introduce the key literature that has examined such new urban landscapes, usually in the form of mega-projects. Often, these are economic projects that entail the development of a mix of retail, industrial, leisure, residential, infrastructural and/or other facilities on large tracts of land, but, increasingly, attention has also been given to the cultural production of space and place, often in monumental proportions, as a means of attracting and sustaining global human and economic flows. We examine the literatures on these cultural icons and their role in urban imaging strategies, in the process highlighting the shift in thinking whereby culture and creativity became important considerations in city competition. Following this, we introduce some of the literature on another dimension of urban 
landscape change that has occurred around arts and cultural activities, namely, the growth of cultural/creative clusters within which cultural/ creative workers engage in cultural/creative production and, often, where cultural consumption takes place. These are typically disused industrial spaces that are transformed, sometimes organically and sometimes via government-led action. Much of this literature draws from cluster theories that are formulated through observation and study of businesses and traditional industries (see, for example, the works of Michael Porter and an even earlier tradition evidenced in Alfred Marshallian ideas), highlighting the agglomeration effects on cultural/creative workers. A critical reading of these literatures helpfully sets the stage for analysing similar, though not identical, urban landscape developments and cultural changes in Asia in subsequent chapters. Much of the existing relevant literatures come from the Western world. In addressing the range of phenomena in the five selected cities in Asia, we hope to seize the opportunity to rethink some of these phenomena.

Finally, this chapter provides an overview of the book chapters and, in so doing, briefly introduces the cities that form the focus of the book.

\section{GLOBAL CITIES AS ECONOMIC PHENOMENON}

When the concept of global cities first emerged, the criteria for identifying a 'global city' were largely confined to the nature and level of economic activity of these cities, such as whether the city served as a key location for banking and financial institutions, transnational corporation headquarters or producer services (Hymer, 1972; Paul, 2004; Reed, 1981; Sassen, 1991). Much of the literature reflected this bias, characterizing global cities as 'staging points for global capital formations and flows and nodes of global governance' (Paul, 2004, p. 592). Global cities specialize in global services and are sites 'where truly global services cluster', often serving as hubs of global supply chains that accommodate the headquarters of multinational firms (Sally, 2014). Global cities follow a market logic - they must be open to trade, foreign capital and migrant workers, with regulatory environments conducive for business. They have also been described as places where 'business - in finance, the professions, transport and communications - is done in several languages and currencies, and across several time zones and jurisdictions' (Sally, 2014).

Reflecting the economic bias in most studies of global cities, numerous indices have been devised to measure the relative competitive position of these cities. These indices not only provided a method of measurement but were also complicit in instigating competitive behaviour. John Friedmann, 
for example, established the notion of a structured hierarchy of global cities (or world cities ${ }^{1}$ ) - a 'hierarchy of spatial articulations' - in which cities can be arranged according to the economic power they command (Friedmann, 1995, p. 23). He provided a means for visualizing a ranked ordering of major cities, based on the nature of their integration with the world economy (Table 1.1) (Friedmann, 1986). Friedmann examined the hierarchy of global cities in two categories - core countries and semiperipheral countries ${ }^{2}$ - assigning cities in each category with the rank of primary or secondary. Global cities of first/primary rank in core countries were identified as London and Paris, and also included Frankfurt, where the West German economy was centred, Zürich, as a leading money market and the Europort of Rotterdam. Singapore and São Paulo ranked highly for semi-peripheral countries. Selection criteria included whether the city serves as a major financial centre, key manufacturing centre and major transportation hub; whether it houses headquarters for transnational corporations and international institutions, with consideration also paid to population size and whether the city's business services sector was growing quickly. Not all criteria were used in every case, but several criteria had to be met before a city could qualify as a global city of a certain rank (Friedmann, 1986, 1995). Given the state of world development during the years in which Friedmann's world city hypothesis was published - first in 1986, then reproduced in Knox and Taylor's 1995 book World Cities in a World-System - his hierarchical ranking did not include cities from countries like India and China since, at that point in time, India and China were only weakly integrated with the world market economy.

Cities of secondary rank in Friedmann's world city hierarchy included cities like Brussels, Milan and Vienna, but Friedmann notes that the list of secondary cities was meant to be only suggestive. He made two observations regarding secondary cities. First, for core countries, secondary cities are usually smaller and more specialized than cities of first/primary rank. Second, for semi-peripheral countries, most secondary cities identified are capital cities (Friedmann, 1986). Above all, he pointed out that intense competition among cities and the volatile world economy meant this hierarchy did not remain stable. Cities are constantly fighting among themselves for more power and control. 'Competitive angst,' he wrote, 'is built into world city politics'. With the competitive position of cities continuously changing, any hierarchical ranking can only remain relevant for a relatively short period of time (Friedmann, 1995, p. 23). The implication was also that cities of secondary rank have a chance to achieve global city status.

Likewise, Peter Taylor's (2000) hierarchy of world cities sought to identify cities with the highest 'world city-ness values'. His framework further demonstrates the hegemonic economic criteria. Even while he 
Table 1.1 Friedmann's world city hierarchy

\begin{tabular}{|c|c|c|c|}
\hline \multicolumn{2}{|c|}{ Core countries } & \multicolumn{2}{|c|}{ Semi-peripheral countries } \\
\hline Primary & Secondary & Primary & Secondary \\
\hline London* I & Brussels* III & & \\
\hline Paris* II & Milan III & & \\
\hline Rotterdam III & Vienna* III & & \\
\hline Frankfurt III & Madrid* III & & \\
\hline Zürich III & & & Johannesburg III \\
\hline New York I & Toronto III & São Paulo I & Buenos Aires* I \\
\hline Chicago II & Miami III & & Rio de Janeiro I \\
\hline \multirow[t]{2}{*}{ Los Angeles I } & Houston III & & Caracas* III \\
\hline & San Francisco III & & Mexico City* I \\
\hline \multirow[t]{5}{*}{ Tokyo* I } & Sydney III & Singapore* III & Hong Kong II \\
\hline & & & Taipei* III \\
\hline & & & Manila* II \\
\hline & & & Bangkok* II \\
\hline & & & Seoul* II \\
\hline
\end{tabular}

Note: * National capital; population size categories (recent estimates, referring to metroregion): I 10-20 million, II 5-10 million, III 1-5 million.

acknowledged John Friedmann's widely used hierarchy of world cities, he was nevertheless disappointed by the lack of methodological clarity. Taylor wrote that 'in his [Friedmann's] original list, we are told "selection criteria include" which implies an incomplete enumeration, followed by a collection of functions (for example, corporate headquarters), processes (for example, growth of business services) and measures (for example, population size). How these are combined is not made clear.' In establishing his own order of world cities, Taylor identified three levels of cities - alpha (the highest), beta and gamma. He looked at four key service sectors - banking/finance, accountancy, law and advertising - and identified cities that serve as prime, major and minor centres for each of these sectors. A score of 3, 2 and 1 was assigned to cities for being prime, major and minor centres in the different sectors, respectively. The scores for each city were summed up and the cities arranged according to their total scores, with the highest score being 12 . World cities were identified as those that scored four and above. The world cities were then divided into alpha, beta and gamma cities, with alpha cities having the highest 'world city-ness values' and gamma cities the lowest. Alpha cities in Taylor's model included London, Paris, New York, Tokyo, Frankfurt, Hong Kong and Singapore. Beta cities included San Francisco, Sydney, Toronto and 
Table 1.2 Taylor's ordering of world cities

World city-ness value

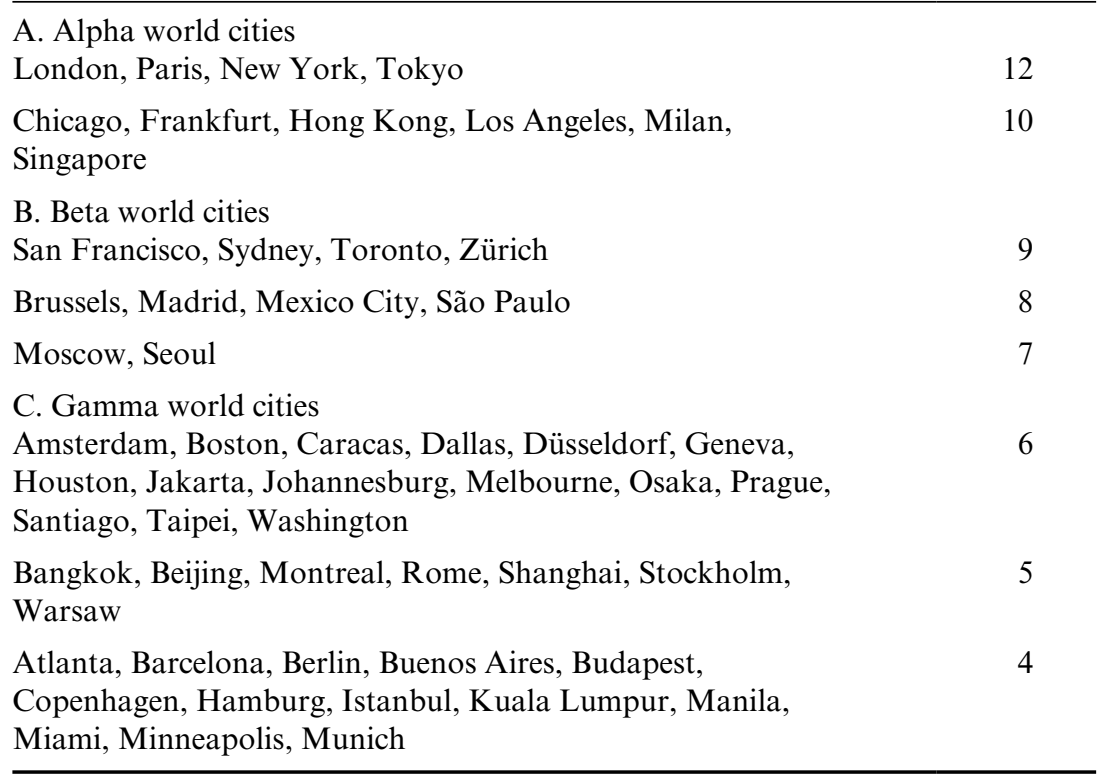

Zürich (Beaverstock et al., 1999; Taylor, 2000, pp. 12-15). A full list of Taylor's alpha, beta and gamma world cities is shown in Table 1.2.

\section{CULTURE IN/OF GLOBAL CITIES}

While early global city studies focused on economic criteria and neglected cultural character, since the late 1990s, academic and policy attention has broadened to consider the place of culture in/of global cities. One body of literature highlights the culture of global cities. Among the most notable is the dynamic transcultural character of such cities. Yeoh (1999), for example, observes that global cities are 'sites of transnational cultural mixing'. Similarly, Hall (2000, p. 646) views global cities as sites where transnational flows of various peoples from various cultural backgrounds occur, bringing in creativity that continually renews the city. He observes that the global city is an 'absorptive, continuously changing terrain that incorporates new cultural elements whenever it can' (Hall, quoted in Sassen, 2000, p. 176). As Jacobs (1996, p. 4) believes, the cultural energy from such transnational urban encounters may be leveraged by cities for economic 
regeneration. Such transcultural encounters bring with them challenges as well: global cities must address inequality and related social issues. The inequality gap in global cities tends to be wider as skilled, educated workers enjoy a larger share of the returns to capital than those lacking in skills. In cities like Hong Kong and Singapore, people have become more sensitive to growing income inequality, more opposed to large-scale immigration and increasingly expect the government to provide more affordable housing, healthcare coverage, pensions and social security (Sally, 2014).

Of particular concern to us in this book is culture in global cities. Competition to become a global city has intensified around the production and consumption of culture and the arts, often taking the form of the construction of mega-projects and hallmark events, the development of a cultural industries sector and an upsurge of urban image-making and branding activities' (Yeoh, 2005, p. 945). Cultural development has thus become indispensable to any strategy of global city building (Bryan et al., 2000; Leyshon, 2001; Scott, 1997, 1999, 2000a), and cities striving for global city status do so on the basis of integrating cultural and economic activity. This is manifest in the production and consumption of the arts, architecture, fashion and design, media, food and entertainment (Yeoh, 2005, p. 946). Municipal authorities are increasingly formulating their cultural policy to include the building of high-profile urban flagship projects, production-based strategies such as channelling more resources towards nurturing the cultural industries and consumption-based strategies through urban imaging and place marketing (Kong, 2000b; Watkins and Herbert, 2003; Yeoh, 2005, p. 946). Increasingly, cities hoping to become global cities recognize that they cannot rely on economics alone, but must also become global cultural cities. As Hall (2000, p. 640) observes, many cities believe creating a new urban image requires culture as the 'magic' ingredient that boosts the attractiveness of a city to mobile capital and mobile professional workers.

As competition among cities for global city status intensifies, more and more cities are turning to the accumulation of cultural capital as an essential part of their strategy. Such cultural assets take the form of cultural facilities and cultural spaces, leading to a new wave of cultural space construction, resulting in new urban landscapes. One key strategy that cities have adopted is the building of top-quality cultural facilities (such as museums, concert halls, grand theatres or art galleries), considered by many cities as essential to achieving and maintaining their global city status (De Frantz, 2005). This line of thinking is further strengthened when the most imageable and prototypical global cities are remembered by their cultural infrastructures. The most obvious examples include the Louvre and Pompidou Centre in Paris, the Tate Gallery and British Museum in 
London and so forth. Cities in Asia striving for global city status have recognized what such cultural infrastructure adds to their project of 'going global' and have, in recent years, adopted the strategy of creating new urban landscapes through the making of cultural infrastructure, often impressive for their size and scale and their architectural distinctiveness.

The development of cultural mega-projects and icons began with the emergence of cultural policy as an urban regeneration strategy, particularly in the 1980s among Western European cities. During this period, declining cities such as Glasgow and Sheffield - which were struggling to find sources of economic growth as the sectors they had formerly relied on were becoming obsolete - turned to developing large-scale cultural projects to serve as 'symbols of rebirth, renewed confidence and dynamism' (Bianchini, 1993b, p. 15). Frankfurt in Germany pursued its global city aspirations by launching a major project to enhance the city's cultural status. It pumped approximately one billion ${ }^{3}$ deutsch marks into constructing high-quality cultural buildings, developing 13 new museums along the River Main and transforming a run-down opera house into a concert hall. More evidence of its increasing emphasis on cultural policy was reflected by the fact that government spending on cultural policy increased from 6 per cent of municipal expenditure in 1970 to 11 per cent in 1990. Paris, under President François Mitterrand, embarked on a series of extensive cultural projects to build its status as the future 'economic and cultural capital of Europe'. It created cultural and architectural icons such as the Louvre Pyramid, the Musée d'Orsay, the Opéra de la Bastille, as well as the Institut du Monde Arabe (Arab World Institute) and Museum of Science and Technology. Similarly, Rotterdam in the Netherlands overhauled its image from that of an industrial centre through cultural projects, such as a new museum of architecture (the Netherlands Architecture Institute) and by developing itself as a site for international film and jazz festivals (Bianchini, 1993b, pp. 16-17). Flagship projects undertaken in the United Kingdom were also crucial in urban imaging. Birmingham's mega-project, for example, was based on urban design strategy and public art policies, and involved building a new concert hall for the city's symphony orchestra, reusing the city's canal system, enhancing the distinctive features of its urban districts, and recreating the city as a site for arts festivals and as a relocation site for London-based arts organizations (Bianchini, 1993b, p. 18; Bianchini et al., 1992). Such cultural flagship projects and icons indeed helped cities to create positive urban images, attract economic investment, develop their tourism sector and enhance their competitiveness (Bianchini, 1993b).

Building top-quality cultural facilities enables cities to host world-class cultural activities or performances, and is regarded as an essential element 
of the strategy to attract high-end artists/performers and cultural elites from around the globe as a means for the city to develop and maintain its competitive advantage (De Frantz, 2005; Kong, 2007; Landry and Wood, 2003). Cultural infrastructure is also justified as fulfilling other functions in city development. It is argued that cultural infrastructure offers artists or cultural workers a creative environment and platform for interaction and physical spaces for citizens to enrich their cultural life. Cultural infrastructure is said to cultivate local artists by developing their linkages to global counterparts. In addition, it is believed that the development of creative industries - such as music, film, visual arts and fashion design - is promoted through the availability of cultural infrastructure. Further, cultural infrastructure can serve to beautify the city through the creation of symbolic icons and images. This can help the city enhance its attraction and bolster its tourism industry. The development of cultural infrastructure can also increase a city's global visibility through the enlisting of renowned architects to design unique, world-class cultural monuments. It is through all these connections that the city can offer its citizens a more diversified and richer cultural life, and thus solidify its cultural development and identity.

The physical fabric of cultural infrastructure/facilities is more tangible than the invisible or non-physical aspect of cultural development; building huge cultural infrastructures has become the prevailing strategy in many Asian cities. These kinds of projects are seen to be an essential part of national development. However, such projects require a huge amount of resources for construction and operation. The state is highly involved and plays an important role in planning, building, organizing and managing the use of these facilities. However, despite the amount of academic and policy attention that the strategy of building cultural mega-facilities has received, voices of dissent against such a strategy are routinely heard.

Critics assert that the competition for culture tourists biases a city's cultural policy towards the commercialization and marketing of its cultural assets. Even if commercialization per se is above reproach, it could turn pernicious on account of its potential to marginalize local participation in the cultural enterprise, truncate other functions of a cultural policy and dilute the city's local flavour. Badly managed, the strategy of constructing showpiece facilities can contribute to and coincide with the depletion of local cultural assets in the long run (Lee, K-S., 2011). This anxiety is justified by pointing out, first, that while these mega-facilities consume large amounts of public resources, their benefits accrue only to a small group of individuals or particular communities. Second, a commitment to these projects diminishes the resources available for the construction of numerous, spatially dispersed, smaller-scale facilities, which are considered 
better able to function as spaces for socialization and cultural education. Further, once the facilities are operational, they mark a shift in resource allocation towards organizing large-scale cultural festivals directed at attracting tourists and external performing arts groups. Consequently, while local cultural activity and local artists suffer in general, a significant burden of this resource squeeze is incident on minority cultural groups (Bianchini et al., 1992; Lee, K-S., 2007). If this trend towards the marginalization of local culture persists, there is a real risk, in the longer term, of what Evans (2003) calls the 'brand decay of the city'.

We draw attention to the critiques that two important scholars have presented. First, Andy Pratt has drawn attention to the need for urban regeneration to reflect a city's unique culture/heritage, which necessarily means developing 'place-bound' strategies. Using the example of the Guggenheim museums, Pratt (2004a, p. 2) observes that culture-based urban rejuvenation projects do not necessarily provide a city with a unique advantage when they consist simply of installing a Guggenheim museum as part of that museum's international franchise. As other Guggenheim museums are found in various countries across the world, the cultural monument is far from being an exclusive, one-of-a-kind asset. Pratt also cautions that 'this trend to sell cities using public money is a socially regressive form of taxation; it is also politically divisive', since promoting elite culture will likely alienate a significant proportion of the electorate (Pratt, 2000a, 2008, p. 112; Zukin, 1995).

Similarly, Allen Scott is wary of embracing elaborate urban rejuvenation projects with uncritical optimism. He notes the growing multitude of programmes driving cities' investment in cultural facilities and emphasizing more culture-intensive forms of production (Scott, 2004) - in cities like Hong Kong, Sydney, Osaka and Singapore but also in places like the Ruhr region in Germany, where heavy-manufacturing infrastructure was recycled to accommodate cultural projects and services production; the Northern Quarter of Manchester; the Cultural Industries Quarter of Sheffield; and the Westergasfabriek in Amsterdam, a former gasworks site converted into a cultural venue (Gnad, 2000; Scott, 2006). This trend of reinventing urban landscapes and engaging in place marketing, which is intertwined with creative city theory, has seen some successes in achieving the desired goals of enhancing the image/prestige of a city, elevating a city's global reputation and its attractiveness to investors and highly skilled labour. Nonetheless, Scott points out such strategies are 'greatly constrained as to both their range of applications and their likely economic results' (Scott, 2004, pp. 464-5) and that, in many other instances, the actual returns on major investment in urban amenities turned out to be much lower than expected. He warns against indiscriminately adopting 
and applying generic models to individual cities (Scott, 2014, p. 9). Essentially, urban development policies should be designed to suit a specific place and period, as simply implementing a borrowed policy or model does not guarantee the desired outcome (Scott, 2006, p. 12). Scott's view is that urban imaging projects which rely on cultural/heritage and place marketing 'need to be put in due perspective, especially by comparison with an alternative (or, rather, complementary) set of approaches that has more recently started to come into focus'. The alternative he refers to here is a policy focused less on urban reimaging and the selling of places and more on the export of local cultural products to markets across the world (Scott, 2004, pp. 464-5).

Like Pratt and Scott, other scholars have raised questions about the viability of the strategy of constructing cultural mega-facilities. Empirical enumerations of the costs and benefits of such projects remain scarce. Studies comparing the actual and expected performance of these venues are lacking as are cross-sectional comparisons between cities with such facilities (Hamnett and Shoval, 2003). This is a surprising oversight given the consensus that, especially in developing countries, the real challenges come after the facility becomes operational. Supporting the operation and management of the cultural facilities generates a continuous appetite for resources. Evans (2005) identifies how the economic mandate for such projects may be jeopardized when visitor and income targets fall short and delegitimize the continued commitment of resources for their operation. In this light, the need for empirical studies that focus on the postconstruction phase of cultural facilities to identify their impact on multiple scales is urgent.

Despite the lack of thorough investigation into the post-construction impact of cultural infrastructure, the strategy of building such cultural mega-facilities continues to be adopted, as we shall demonstrate through our focus on five Asian cities. However, though investing in cultural megaprojects has shifted culture to the forefront of strategies for improving a city's image and its competitive positioning, there is recognition that hardware alone is insufficient. To attract investors and high net worth, skilled global workers and migrants to their cities, city governments have recognized the need to offer an exciting and vibrant cultural life, to which cultural monuments and icons play a role, but which entails more than that. Cities have therefore adopted consumption-based strategies that take the form of urban imaging and place marketing, building a global image and attracting flows of global elites and tourists (Landry and Wood, 2003; Strom, 2002; Zukin, 1995). One approach has been to host hallmark events, ranging from the Olympics (Beijing) to the World Expo (Shanghai), as well as major cultural events, such as Tresors (Singapore), 
art biennales (Taipei, Beijing, Shanghai, Singapore) and architecture biennials (Hong Kong). Hall (1993, p. 891) cites the example of Barcelona, where, since hosting the 1992 Olympics and using the Olympic Village as a site for urban renewal, the city has launched other urban rejuvenation projects such as the Forum-Besòs project, centred around an Arts Forum (EUKN, 2006). The Arts Forum - a cultural fiesta comprising art exhibitions, concerts, dance and theatre performances - near the River Besòs served as the impetus for transforming and investing in new urban infrastructure in the area (EUKN, 2006; Riding, 2004). Furthermore, effort has been made - though with much more difficulty - to develop a lively local arts and cultural scene in order to provide a diverse cultural life for the city's residents (Goldsmith and O'Regan, 2004; Watkins and Herbert, 2003). The urban imaging strategies that cities undertake, both in the form of elaborate and monumental mega-projects and mega-events to create positive images and the perception of global status, are 'in their essence the pursuit of an ideal, a vision of the city's identity as much as its levels of capital investment, employment or income' (Paul, 2004, p. 574). While an important topic in itself, the study of mega-events must be left to another book; we have chosen to focus in this book on cultural spaces in urban landscapes.

Apart from the production of cultural mega-structures and the hosting of mega-events, initiatives have been introduced to grow (culture-based) creative industries. As mentioned earlier, this is a production-based strategy and is closely associated with urban landscape change, as subscription to the normative theory of clustering leads to the development of creative clusters or creative parks, as they are sometimes termed. We return to this in the next section.

We draw attention to one final point before turning to cultural creative industries and the spaces they occupy. Departing from the obviously economic criteria of Friedmann and Taylor, in recognition of the growing role of creativity in the economy and its potential in boosting a city's competitiveness, Richard Florida has developed an index for measuring the creativity of a city. Florida is best known for his concept of the creative class, in which he posits that in order for economies to grow and compete they need to attract the so-called creative class of workers to leverage creative energy for their development, as he believes human creativity is the ultimate economic resource (Florida, 2005). His theory of economic growth, as articulated in his book The Rise of the Creative Class (Florida, 2005), has attracted considerable controversy, with critics charging that his creative class theory is elitist and questioning the soundness of his methodology and data (Clark, 2004; Glaeser, 2004). Nevertheless, the Creativity Index developed by Florida remains a method by which 
competition among cities has been studied (see, for example, CCPR, 2005). It is intended to serve as an indicator of a city's overall standing in the creative economy, by measuring the creative capabilities of a particular place. The Creativity Index is a composite indicator made up of four equally weighted factors: (1) a Creative Class Index; (2) a High Tech Index; (3) an Innovation Index; and (4) a Gay Index (Florida, 2002b, p. 6, 2005, pp. 332-4). The Creative Class Index shows the percentage of creative workers in the workforce. The High Tech Index acts as a measure for high-technology industry, while the Innovation Index is a measure of patented innovations per capita. Finally, the Gay Index is a measure of the representation of gay people in a region relative to the country as a whole, and serves as a gauge for diversity or as a proxy for the city's openness to diverse people and ideas (Florida, 2002b, p. 16, 2005, pp. 332-4). Cities are ranked according to their overall Creativity Index score, providing an indication of their competitive position. Although not explicitly about global cities, Florida's Creativity Index provides another yardstick by which cities compete.

\section{THE SPACES OF CULTURAL CREATIVE INDUSTRIES ${ }^{4}$}

Cities in Europe and other parts of the world have subscribed to the idea that cultural or creative industries form the basis for economic regeneration (Hall, 2000, p. 640) and increased competitiveness. These ideas have 'travelled' to Asia (J. Wang, 2004), albeit unevenly (Kong et al., 2006). The normative script is characterized as follows. To compete in the new creative economy, cities should seek to implement particular initiatives: encourage creative industry clusters; incubate learning and knowledge economies; maximize networks with other successful places and companies; value and reward innovation; and aggressively campaign to attract the 'creative class' as residents (Gibson and Kong, 2005). In this book, our focus is particularly on the adoption of creative industry clusters as an urban strategy.

'Clusters', or the co-location of specialized industries, are not new. The phenomenon has been acknowledged since 1890, with the writings of Alfred Marshall, who noted the 'concentration of specialised industries in particular localities' (Martin and Sunley, 2003). Since then and in more recent years especially, a number of authors have attempted to develop conceptualizations of such concentrations.

Most of the literature has focused on industrial or business clusters, which have drawn the attention of many policy-makers seeking to 
promote national, regional and local competitiveness, innovation and growth. Drawing particularly on the work of Porter $(1998,2000)$, the following refrain has developed about the benefits of clustering: it delivers higher rates of innovation because it allows rapid perception of new buyer needs; it concentrates knowledge and information; it facilitates ongoing relationships with other institutions including universities; it allows for rapid assimilation of new technological possibilities; and it provides richer insights into new management practices (Simmie, 2004, p. 1096). Much attention has also been paid to the transaction cost advantages and increasing returns to scale that arise from clustering, as well as less measurable benefits such as the building up of social capital (Fukuyama, 1995), tacit knowledge and informal networks, and the 'cafeteria effect' (Konstadakopulos, 2000). This adds to the explosion of literature acknowledging how inter-firm learning is facilitated with concentrations of firms, institutions and labour; how interactions between different agencies, including government agencies, are enhanced; and how understanding of client needs are sharpened (see, for example, Amin and Thrift, 1994; Cooke, 2002b; Grabher, 1993; Scott, 1996, 2001; Scheff, 2001; Storper, 1997).

How might all of this be relevant to cultural/creative clusters? It is a question that deserves to be asked, but which has been elided once too often. The cultural/creative cluster is too often conflated with business and industrial clusters, and subjected to the same economic analysis and policy response as other industries. This is unsatisfactory, as many creative clusters are "de facto cultural quarters with assorted cultural consumption and not for profit activities' (Evans et al., 2005, p. 26), thus meriting evaluation through a different lens. The relevance and supposed benefits of applying cluster logic to the cultural/creative industries may be described as follows. Cluster logic posits that concentrations of related activities produce 'creative milieux' (Hall, 2000) or 'creative fields' (Scott, 1999, 2006) in which exist structures that encourage learning and innovation, and social relations that exhibit trust, mutuality and cooperation. These institutions and networks are socially constructed and culturally defined, as well as deeply embedded in local contexts. Cultural and artistic communities located in physical propinquity are thus 'not just foci of cultural labour in the narrow sense, but are also vortexes of social reproduction in which critical cultural competencies are generated and circulated' (Scott, 1999, p. 809). They attract other talented individuals, who migrate to join these communities. These communities are 'collectivities' whose members are engaged in 'mutually complementary and socially coordinated careers' and are 'repositories of an accumulated cultural capital' (Scott, 1999, p. 809). Institutional infrastructure such as schools, training and apprenticeship 
programmes, workers' organizations and industry associations serve to sustain cultural capital within the community. These features serve as an overarching order, the 'industrial atmosphere' that Marshall (1919, cited in Scott, 1999, p. 809) referred to almost a century ago.

In addition to coordination, cultural communities that group together benefit from sharing codified as well as tacit knowledge. The latter implies that knowledge is embedded locally, thus cultural producers need to be 'inside' the circuit of knowledge. Consequently, the cultural sector relies on a network of creative producers. Collective learning and transfer of knowledge arise from such frequent interactions within a cluster (Bassett et al., 2002, pp. 172-3; Capello, 1999). Further, with 'insiders' knowledge and immersion in the local scene', the 'vital innovations and mutations' take place and the 'creative work gets done' (O'Connor, 2004, p. 136). Such work involves the transformation of signs, the creation of 'a style, a look, a sound' by local culture, made possible because the city (and the cluster) has acted as a 'crucible' (O'Connor, 2004, p. 134). Such placefocused cultural work results in cultural products often becoming associated with particular locales; the consequent 'reputation effect' becomes the source of location-specific monopoly rents (Scott, 1999, p. 810).

Efforts to improve our conceptual understanding of cultural/creative clusters have drawn attention to the following additional distinguishing dimensions. The first is an acknowledgement that location is not only about a physical coordinate, or indeed about relative location - that is, location in relation to other activities. Instead, it is about 'the particular traditions, conventions and skills that exist in any given urban area [that] help to infuse local products with an exclusive aura that can be imitated by firms in other places but never completely reproduced' (Scott, 2006, p. 10). Location is thus about the unique character of a place that shapes the nature of the cultural product. Where a cultural cluster exists matters because it moulds the specific identity and character of the cultural product, whether it be music, art or poetry.

The second distinguishing quality of cultural/creative clusters is the fact that cultural producers need to be 'inside' the circuit of knowledge where 'insiders' knowledge and immersion in the local scene produce the vital innovations and mutations' (O'Connor, 2004, p. 136), because the unique 'style ... look ... sound' of 'local culture' cannot be transmitted formally as codified knowledge. The (re)production of a cultural product is dependent on such a nuanced and tacit understanding of the qualities of a place and the character of a product.

The promise of clusters has led to enthusiastic development in numerous cities, including those we study in this book. Cities have taken to redesignating existing spaces to perform cultural functions and recycling 
urban spaces as creative clusters, in the hope of boosting their cultural and artistic capacity. Examples are old urban spaces that have been converted into working space for artists and, in some instances, industrial parks for the concentration of creative works and cultural entrepreneurs (Grodach and Loukaitou-Sideris, 2007; Hitters and Richards, 2002). Potts and Keane (2011) documented the 'several distinct, although overlapping stages' of the formation of cultural/creative clusters in China, which was led by various city governments. A first wave comprised spaces dedicated to industrial design, antiques, animation and sculpture. A second involved artist zones and cultural districts, followed by media content clusters (especially animation). Stand-alone cinema, television and animation production centres followed and, finally, the incubator model emerged, 'often with a purported emphasis on R\&D, and often with the declared intention of making science parks more "creative" (Potts and Keane, 2011)

While the above demonstrates that there have been efforts to conceptualize and categorize clusters, including cultural/creative clusters (for example, Bassett et al., 2002; Evans et al., 2005; Flew, 2005; Mommaas, 2004; see also Kong, 2012b), conceptual models are often built on theoretical logics not always grounded in in-depth ethnographic analysis of empirical phenomena, let alone in different parts of the world and under different circumstances where different logics may prevail. Zukin's (1982, 1989) well-known work on the concentration of artists living in lofts in downtown as well as midtown Manhattan and Brooklyn remains one of the most memorable and richly detailed works that deserves to be emulated. As she details, the movement into and settlement of cultural/creative workers in Manhattan, New York City, stimulated the transformation of the former industrial area into a vibrant artistic district. Until the end of the 1960s, Lower Manhattan's urban landscape consisted mainly of manufacturing compounds and stores, along with ethnic neighbourhoods and some newer office buildings. Garment factories, printing plants, small manufacturers of mechanical and consumer goods, distributors and suppliers occupied the area. Towards one end of Lower Manhattan stood a group of nineteenth-century, multi-storey loft buildings with large, open spaces on each floor formerly used by manufacturing firms (Zukin, 1982, pp. 259-60). Due to changes in production processes that required even more floor space, these manufacturing firms had relocated from the lofts to larger premises elsewhere. The general feel evoked by the remaining loft buildings was one of urban decay; both vacancy rates and rents there remained low. However, from around 1961, artists began to move into these lofts in downtown Manhattan as well as midtown Manhattan and Brooklyn, as part of New York City's growth as a world art capital 
(Zukin, 1982, pp. 260, 263; 1989). Artists were attracted to the lofts not only because of the low rent but the expanse of floor and window space, which made them suitable as live-in studios. The high ceilings were particularly useful for exhibiting large works of art (Zukin, 1989, p. 2). More and more lofts were soon converted into studios for artists and musicians, home offices for writers or used to house new service-sector cottage industries such as fashion design (Zukin, 1982, p. 257). Loft buildings became 'artists' quarters' where artists held exhibitions; they drew art dealers, museum curators and collectors (Zukin, 1989, pp. 2, 4). The urban environment thus began developing into a place for arts and cultural activities, and a site for cultural production and consumption. Visitors to the area were impressed by the stylish lofts done up by artists, and the public began to pay increasing notice. By around 1970, lofts had been transformed into a symbol of 'bourgeois chic', attracting large numbers of middle- and upper-middle-class people who began to move in and live in lofts (Zukin, 1989 , p. 2). Zukin surmises that loft housing attracted those in search of the unconventional: 'closet hippies' seeking 'marginal chic'. The idea of residing in post-industrial spaces perhaps appealed to people's sense of art and history, space and time. Artists' living habits had become 'a cultural model for the middle class' (Zukin, 1989, pp. 14-15). Some of the new middle-class residents paid architects and designers to carry out major renovations to their lofts. As this urban resurgence continued and more lofts became converted for residential use, investors and professional real estate developers began to take notice and get involved. The real estate market in lofts grew further (Zukin, 1989, pp. 2-3). Over time, loft buildings and the manufacturing districts where they were located were transformed into residential and commercial spaces. Stylish loft residences and boutiques of cultural consumption burgeoned in areas formerly monopolized by factories or warehouses (Zukin, 1982, pp. 256-7). Although Zukin's study of New York lofts was not focused on the dynamics within the cluster, which so much of the literature has tended to valorize, it succeeded in demonstrating how urban landscape transformation can be driven by arts and culture, and the role of arts/culture in enabling social and economic change (Zukin, 1982).

While Zukin's work has long been in circulation, and the phenomenon she describes and analyses is well known, the empirical case in other contexts needs to be carefully made. Rather than assuming that the relationships and processes in Manhattan and Brooklyn, or those in Porter's business clusters and Marshall's industrial clusters, will be replicated elsewhere, there needs to be detailed empirical and ethnographic work conducted of other places and experiences in order to draw up more robust theory about clustering and urban change. As Martin and Sunley (2003, 
p. 28) observed, the empirical case for clustering remains unclear; 'explanation of causality and determination' has become 'overly stretched, thin and fractured'. Even though Martin and Sunley were mostly focused in their critique on the economic benefits of clustering, their concern to have sound empirical evidence of causality is pertinent here in relation to cultural and creative workers and groups, though they sometimes (or often) differ in being non-profit groups; the questions asked about the value of physical proximity must thus be focused on other kinds of benefits. Today, there remains a severe shortage of micro-level analyses of cultural/creative clusters at ground level, and theory built up from there. This book is motivated in part by a desire to contribute to the micro-level understanding of specific sites in the hope of contributing towards a more refined and robust theory of cultural/creative clusters.

\section{METHODOLOGY}

Before we introduce the cities that form the subject of analysis in this book, we add a short note on our methodology. The material for this book is drawn from detailed ethnographic fieldwork conducted by the three authors mainly over a four-year period from 2007 to 2010. Interviews were conducted with a total of 226 individuals across the five cities (35 in Beijing, 55 in Shanghai, 51 in Hong Kong, 51 in Singapore and 37 in Taipei). Among those interviewed were arts practitioners (visual artists, theatre practitioners, gallery curators, exhibition organizers, designers and so forth), gallery owners, café owners, local scholars, arts educators, officials in various government agencies (such as urban planning departments and art councils), and cultural facility and cultural cluster managers. During the fieldwork period, we made numerous visits to all the cultural monuments and creative clusters covered in this study, including the studios, galleries, cafés and other facilities within. We were participant observers, studying, inter alia, visitor rates, audience make-up and programming (often, performances and exhibitions). We also relied on various other sources of information, including the local newspapers in each of the cities, magazines, online reports, policy documents and significant speeches by government leaders. In sum, we believe that the rich ethnographic detail afforded by painstaking fieldwork, set within the broader contexts of the economic, political and cultural changes in these cities, as drawn from primary and secondary documentary analysis, will provide many new insights into the arts spaces and new urban landscapes of the five (aspiring) global cities. The empirical material thus collected 
will also contribute to a better understanding, if not reformulation, of various theories.

\section{ORGANIZATION OF THE BOOK}

Following this introductory chapter, the book comprises ten substantive chapters divided into two parts. Part I examines the construction of cultural mega-facilities, the hopes invested in them and the challenges faced in their construction and subsequent consumption. The five chapters in this part, each focusing on one city, tell a story of global city aspirations, the use of a cultural (infrastructure) strategy and the urban change that is attendant on such a strategy. Part II focuses on the same five cities, this time addressing a different kind of arts space, that of clusters, sometimes organically evolved, other times state-implemented and yet other times business-led. Through the reuse of old factories and schools, new urban landscapes emerge that contribute in varying degrees to the cultural and creative lives of the cities. Following the ten substantive chapters, the final chapter summarizes observations and draws together lessons learned in order to refine and sharpen theoretical understandings of arts spaces, new urban landscapes and global cities.

We have chosen to focus the first of the book's substantive chapters on Beijing because, in one sense, it may be described as a city of monuments. From the Forbidden City to the Summer Palace, from the Great Hall of the People to Chairman Mao's Mausoleum, this city with its ancient history is full of mega-structures that speak of the grandeur and political power of another time. Chapter 2 contextualizes the development of one of the latest cultural infrastructure projects - the National Grand Theatre - by tracing the ideological and policy shifts that have shaped the production of cultural space in Beijing, highlighting the early use of cultural space as a tool for nation-building, the more recent treatment of culture and space as capital in the period of Reform and Opening Up and the still more recent period of building Beijing into a global city. The chapter focuses particularly on the discourse and reality surrounding the construction of the National Grand Theatre in Beijing's cultural landscape. Three sets of questions are addressed. First, the genesis of and motivation behind the construction, as well as the building strategy and process, are examined. Second, the construction of a new urban cultural space and the changes wrought foreground diverse issues such as architectural design, public project safety, the changing city image and so forth. The ways in which these issues were debated, the public discourse generated and the insights gained of the relationship between the state and public participation are all 
examined. Third, since completion in 2008, the National Grand Theatre has been subject to multiple interpretations; the different rewritings and rereadings of the new cultural landscape by various communities within Beijing are analysed.

Following this chapter on Beijing is, unsurprisingly, a chapter on Shanghai (Chapter 3), a city that has long felt a sense of rivalry with the national capital, desirous as it is to gain primary position within the national imaginary and, simultaneously, the world stage. In its efforts to pursue global city status, Shanghai has devoted significant resources to develop its cultural infrastructure in order to support 'global' cultural activities as well as flows of global elites, tourists and investments. This cultural emphasis is also intended to assist local cultural development, to solidify civic identity and to promote the cultural sophistication of its citizenry. By examining two of the most significant cultural projects in recent years, namely, the Shanghai Grand Theatre (SGT) and the Oriental Art Center (OAC), this chapter examines the ways in which cultural infrastructure projects have been used to promote the city's global status, as well as what these cultural infrastructure projects mean to various groups in Shanghai. In particular, the chapter introduces the top-quality facilities at these cultural mega-projects that have managed to attract a range of global cultural activities, thus promoting Shanghai's city image and cultivating a sense of pride. SGT and OAC have also attracted 'high class' audiences from nearby provinces and international tourists, promoting Shanghai's status as a cultural centre in the Yangzi Delta region in southeastern China, and even in China and the Asia-Pacific region. However, due to Shanghai's ambition to be a global city and the high costs of operating top-quality facilities, SGT and OAC seem to cater exclusively to tourists and local elites. Lacking are efforts to draw in local residents as audiences and strategies to support local art groups that develop local cultural contents. While it is relatively easy to build cultural infrastructure in the short run, fostering art and cultural appreciation needs long-term planning and development. The growth of an art-appreciating population, the maturation of local artists and the availability of space for local art-workers are requisites for economic development based on cultural industries. Thus, while investments in 'high culture' facilities have the potential to enrich cultural life, the promotion of local cultural development is necessary for cultivating the artistic and cultural sensibilities of the resident population.

Unlike in Beijing and Shanghai, where major cultural infrastructure construction has transformed the urban landscape, in Hong Kong, the large cultural infrastructure project is still being constructed. Chapter 4 focuses on 'Asia's world city' and how it sought to get an iconic project off 
the ground - taking more than a decade and a half. The idea of a cultural district in West Kowloon was first mooted in 1996 after the Hong Kong Tourist Association released the results of a survey it had conducted, in which 1.3 million of the tourists polled expressed an interest in arts and cultural and entertainment events. The association thus proposed that more large-scale performance venues be developed. The plans of the early 1990s were for the land at West Kowloon to include a park, for commercial and residential development and government or community uses, but in 1998, informed by the tourist association's research and ideas, the thenChief Executive, Tung Chee Hwa, announced the government's plan for a new performance venue in West Kowloon. In 1999, it was specified that the 40-hectare site in West Kowloon would facilitate the development of an integrated arts, cultural and entertainment district. Since the announcements of over a decade ago, there have been many twists and turns in the plans for the West Kowloon Cultural District, as it has come to be called. The chapter analyses the many public responses to the plans, the ways in which civil society organized itself in opposition to what they saw to be a property development under the guise of an arts and cultural hub and the official efforts to respond to the public and interest group protests. The economic imperatives were thought to get in the way of real cultural and artistic development; the (de jure) democratic openness of Hong Kong society enabled the participation of many individuals and civil society groups. The result is that Hong Kong's answer to the many new cultural monuments being established in rival cities in Asia still remains to be completed after more than a decade and a half.

Singapore and Hong Kong are often compared with each other - the next chapter on Singapore (Chapter 5) allows for the situation of the two benchmarked cities to be analysed side by side. Singapore, as with the other cities examined in this book, has global aspirations to be in the superleague of cities. Indeed, some argue that it can already claim global city status, as a linchpin of the new global capitalism. At the same time, this city-state is ceaselessly engaged in the project of nation-building and the construction of national identity. In all of this, a cultural focus has been acknowledged as an important component of the city-state's overall strategies; the development of new cultural monuments has, in turn, been a part of the cultural strategy. At the same time, the cultural strategy is an economic one, recognizing the potential of the cultural industry to generate income and contribute to the city's economic growth. Cultural ambitions in Singapore are expressed in terms of a desire to be a 'Renaissance city' and a 'global city for the arts'. In terms of major cultural infrastructure, the Esplanade - Theatres on the Bay and the renovated and extended National Museum are among the major enhancements to the hardware 
supporting the performing and visual arts in the city. Yet, while acknowledging that global cities have world-class cultural infrastructure, the arts community in Singapore has argued that providing the 'hardware' (infrastructure and facilities) without concomitant attention to the 'software' (creative development) has a regressive effect on the development of local/ indigenous arts. For members of the arts community, the development of large cultural infrastructure attracts large exhibitions and performances, but leaves little room for local communities to develop their own art forms. While a global flavour is apparent, so too is the absence of welldeveloped indigenous arts. The local arts community thus sees Singapore as 'a kind of emporium for the arts', offering yet another retail space, which they fear will stymie the blossoming of local styles and the maturing of national identities. No global city is worth its salt if it does not have a strong base of indigenous works that express local flavours, showcase local idioms and styles and develop national identities. The chapter thus focuses on Singapore's evolution in the successful provision of cultural infrastructure next to its search for a local voice and local styles.

Of all the cities examined in this volume, Taipei is the one city that has perhaps had the most troubles economically and politically in recent years. In that sense, its energies have been absorbed; the ambition of being a global city with its concomitant projects and strategies has perhaps seemed less urgent and pronounced. The idea of developing a major arts and cultural facility came late to Taipei, in 2004. Chapter 6 - the last chapter in Part I - begins by setting out the political and economic contexts in Taipei and the ways in which they have influenced the evolution of cultural infrastructure developments in the city. It then analyses the impacts of such infrastructural developments on Taipei's cultural workers, particularly artists, and on the cultural life of its citizens. It explores the dynamics of global-local cultural interactions and the influences of such dynamics on Taipei's urban landscape. As the capital city, Taipei is the main site of Taiwanese cultural infrastructure investments, such as the National Palace Museum, the Sun Yat-sen Memorial Hall, the National Theater and Concert Hall. All these facilities have had their political functions since 1949. On the one hand, these facilities helped the Republic of China (ROC) government declare to the world that Taipei still had legitimacy in Chinese cultural production. On the other hand, they were used to implement ideological education in order to unite the people against communism. The situation changed in the early 1990s, when the government rescinded martial law and implemented democratic processes. Accordingly, many assembly halls previously used for political functions were released for cultural and art performance use. This change has restructured Taipei's cultural landscape significantly. It now offers 
space for the development of the performing arts as well as provides its citizens with more diversity in the arts. Since the late 1990s, due to globalization and competition from other cities, the state has recognized the ability of special cultural assets to offer competitive advantage and secure its global city status. Decision-makers thus planned to construct new cultural infrastructure aimed at accumulating Taipei's cultural assets and promoting civic cultural life. In the development of Taipei's new central business district (CBD), Xinyi Center, the state succeeded in mobilizing private resources to build the Novel Hall for Performing Arts. At the same time, in acknowledgement of the enlarging audiences for the performing arts and of the competition from other cities in the Asia-Pacific region, many domestic performance groups and artists called on the state to construct a new concert and theatre hall to support performances, particularly international, high-end performances. In 2004, the central government proposed a construction plan for building the largest theatre in Taiwan, the Taipei New Grand Theatre, in the new Banqiao CBD of Taipei County. Due to the huge financial investment needed, the state sought to mobilize private developers' resources once again but the plans received support from neither the state nor the cultural community. The failure of the plan stimulated the newly elected Taipei mayor to put up plans for another facility instead - the Taipei Performing Arts Centre - with investment from the city. Taipei's situation offers different insights from that of the other cities examined in this book. Here, cultural life is active, with a large number of performing arts groups, including some internationally acclaimed ones. Yet, the construction of cultural infrastructure has not caught up with the quite mature cultural and performing arts scene and the level of cultural appreciation of the citizens. This is not because of a lack of vision; rather, the inability to implement the state's plans can be attributed to political disputes and unstable administrative arrangements.

The chapters in Part II consider another dimension in the evolution of global cultural cities. This is the use of old urban landscapes in new ways as part of the artistic and creative life and the cultural/creative economy of the cities, particularly in the form of cultural clusters.

Chapter 7 returns to an analysis of the situation in Beijing, beginning with an investigation of the policy discourse and practice for the development of cultural creative industries, addressing both organically evolved clusters and the state-led cluster strategy for cultural creative industries and their impacts on the development of cultural creative work. This is the context of a specific analysis of the space now nationally and internationally known as '798' or 'Dashanzi'. The original organic development of the cluster in former factory space was facilitated by low rents at the turn of the century, which attracted artists from Beijing, other parts of China 
and overseas. We examine the conditions that supported the development of the arts cluster and the growth of a nascent, socially embedded cultural network. Subsequently, as the government and the Seven Star Group began to be interested in its development, conflicts emerged; we examine the multiple and complex relations between artistic networks and state interventions. The chapter makes the point that much cultural space construction in Beijing is a state-sponsored effort, as is the approach to creative cultural clusters, emphasizing physical infrastructure construction while neglecting the construction of artistic networks and institutions. The 798 case presents evidence that the state attempts to establish and predetermine a developmental path, rather than promote the indigenous growth of artistic creative networks. The result of state interventions was the lack of a conducive environment that supports organic and indigenous development of cultural space.

We then turn to Shanghai in Chapter 8. As with numerous other cities in Asia, Shanghai has sought to promote its creative industries as part of its urban competition strategy, through which it seeks to maintain its global status and functions. One of the key approaches adopted is the revitalization of vacated industrial premises through the establishment of 'creative clusters' or 'creative precincts/parks' to house artists and other creative workers. Since 2006, the city government has approved over 100 creative parks. This chapter examines the driving force behind the development of creative clusters in Shanghai and documents the ways in which the urban landscape is changing as a consequence. It also explores how vacated premises are used to assist artists and develop Shanghai's creative industries. It then evaluates the effects of the development of these creative clusters on the city's cultural and spatial development. The chapter uses three cases to examine the evolution of Shanghai's creative clusters and the interactions and dynamics among different key actors. These clusters are M50 at Moganshan Road, Tianzifang at Taikang Road and 1933 at Hongkou District. M50 and Tianzifang are first-generation projects in Shanghai's development of creative clusters, while 1933 is a newly developed cluster. M50 and Tianzifang have undergone a more organic evolution than 1933, supporting creative industries with cheap space for artists. Tianzifang in particular has been the site of significant interaction with the community immediately surrounding it, thus contributing socially. From a cultural perspective, M50 and Tianzifang are also clusters that have 'real content', having attracted some top artists in Shanghai. Galleries in these two clusters mostly exhibit Chinese contemporary artists' works rather than foreign artists' work. They thus contribute to the longer-term sustainability of Chinese art and culture, although they also face many issues in their current and future development. In contrast, the state has 
intervened to a large extent in the development of 1933. Originally slated to become the essential place for leading design and innovation work, it was to have cultural, educational, entertainment and food and beverage businesses located on its premises. However, its space is mainly for consumption rather than artistic creation. After a period of slow development, it has now witnessed the opening of many shops, restaurants, wine bars, clothing outlets and other consumption spaces. Despite the support of the government of Hongkou District, the project has not become a space of creative production.

In Chapter 9, we turn to Hong Kong, the cityscape of which is usually associated with modern, high-rise, gleaming structures and towering skyscrapers. But Hong Kong also has its fair share of old factories, depots, warehouses and such, associated with its more industrial face. In this chapter, some of the transforming urban landscapes of Hong Kong are introduced as emergent spaces for the arts. These cultural clusters are found in industrial estates, factory spaces and old depots. We focus on two different clusters of arts activities in Hong Kong - one that exists amid functioning factories and another that occupies a former quarantine depot for cattle. Through these cases, we analyse the differences between organically evolved clusters and those with a high degree of government management. The first of the two clusters is in the Fotan industrial estate in the New Territories, where units had become available at highly affordable rent and sale prices post 1997, when many factories relocated to China, a situation exacerbated in 2003 when severe acute respiratory syndrome (SARS) struck and affected the Hong Kong economy particularly negatively. Art students from the nearby Chinese University of Hong Kong and other visual artists as well as some performing artists, architects, designers and others in the creative industry began to rent and buy units in the factory spaces, particularly from 2000/2001. Occupying units scattered across floors in the high-rise factories as well as across factory buildings, the largely young artists have found the organically evolved cluster a positive environment for their art, even though the factory buildings are old, even dirty and smelly, and still used for industrial purposes as diverse as food processing, furniture-making and warehousing. The value of such an environment, particularly as a site of artistic production, is examined and set against a second cluster, the Cattle Depot Artists Village, a heritage site leased by the government to a small group of performing and visual artists since 2001. While appreciating the space that they have, the groups occupying Cattle Depot are clearly frustrated by the restrictions and constraints imposed on them by government authorities, as well as the lack of coordination across government units. The combined efforts to organize themselves are examined and the key strategy of turning the 
government-sanctioned private space into an artistically vibrant public space is analysed.

The idea of reusing old factory space for artistic purposes is similarly evident in Taipei (Chapter 10). Here, the failures and marginal successes of the 'cultural parks' developed out of abandoned factories draw attention to the real needs of the artistic community, as opposed to those based on the received wisdom about the value of clustering and reuse of industrial space. One essential characteristic of cultural/creative clusters that emerges is that spatial proximity is not a necessary condition for artists or creative workers in their production process. Their 'production' sites are by no means limited or fixed to a specific locus, for example, within the premises of cultural parks. More importantly, creative workers need a place that has abundant cultural assets, alongside an environment that is able to support and stimulate them. On the one hand, artists need affordable working space (studios) for carrying out their creative work (production space). On the other hand, they need a place to display their products, to interact with other creative workers and to collect or obtain related information in their field. All these activities require a space that can attract a mass population to come to see and purchase their artworks or creative products. This is the exhibition and consumption space, which should be in a convenient location, with a comfortable environment. These essential differences between the spatial needs of cultural creative production and those of cultural consumption give rise to different kinds of urban landscapes for the arts. This chapter focuses on three case studies to analyse how Taipei reuses its old urban space to support the arts and its related cultural industry. The three cases in question are Huashan Park, Chienkuo Beer Factory and Sungshan Cigarette Factory. Huashan Park originally housed wine factories and warehouses, but was abandoned in 1997. Artists moved in and held an international arts festival there. At the same time, the premises provided space for artists to carry out their creative work. We trace the growing government involvement in its development, with several concomitant shifts: the involvement of private sector management; the increasing profit-making imperatives; the transformation of a cultural production space into an exhibition and consumption space; and the shifting scale of focus, from an emphasis on international events to its role in national life. The second site is the Chienkuo Beer Factory, the earliest brewery in Taiwan, founded in 1919. Through an analysis of the changing fates of the factory space, we demonstrate the role of local cultural organizations, the trade unions associated with the brewery workers, and the surrounding community in shaping its current role in the urban and cultural life in Taipei, including its preservation from demolition and its redevelopment 
as a cultural park. The last site is the Sungshan Cigarette Factory, located in the city centre. Since it stopped production in 1998, there have been many disputes over the use of the facility. The city government's proposals to convert the site to a cultural park and a stadium have met with opposition from residents and environmental organizations. At the same time, the city government failed to contract out the development and operation of the cultural park due to the risk of uncertainty in its operation and the high costs of repair and maintenance of historical buildings. Its plan to use the site for exhibitions, performances and public interactions, as well as to offer affordable spaces to creative workers, has not attracted any willing developers. The cases in Taipei that we analyse in this chapter highlight the fact that the main contributions of the government in the development of the creative industry are in offering vacated public space to creative workers and establishing a liberal environment to stimulate their creative activities. To intervene too much in urban landscape change or to set too many goals in cluster development may not truly help the creative industry.

Whereas the conversion of old factory spaces into new landscapes for the arts is by now common in many cities around the world, and certainly in all the other cities that are the focus of this book, the situation in Singapore lends itself to a different analysis, and thus brings up the rear in the order of chapters (Chapter 11). The flight of industry to China as evident in Hong Kong did not feature as strongly in Singapore. Nor was the closure of state-owned factories, as in China, experienced in Singapore. Old factory spaces are thus not in the same abundance in Singapore as some of the other cities examined in this book. On the other hand, the global cultural city that Singapore aspires to be has benefited from change in another dimension of the urban landscape - the relocation of schools and the resultant availability of old school buildings for alternative use. There are numerous examples: the former St Joseph's Institution now houses the Singapore Art Museum; the former Tao Nan School boasts the Peranakan Museum; the former Convent of the Holy Infant Jesus is a high-end retail complex; the former Stamford Primary School is Stamford Arts Centre; the former Methodist Girls' School was for a time a creative cluster called 'Old School'; and the former Telok Kurau South Primary School is part of the Arts Housing Scheme run by the National Arts Council (NAC) offering space to artists, known since 1997 as 'Telok Kurau Studios'. We focus in this chapter on the last two cases, where old urban spaces have become creative cultural clusters whether by organic evolution or design; we examine the ways in which these new uses have contributed (or not) to creative cultural activity, and ultimately to the ambition and ideal of a global cultural 
city. The case of Singapore's Telok Kurau Studios demonstrates how, contrary to the claims of cluster proponents, creative aesthetic work is accomplished in spite of the creative cluster, not because of it. It is not the synergistic relationships envisaged of clusters that has supported the creative aesthetic work of the artists. Instead, the relationships within the cluster are marked by hostility and rivalry. There is a lack of dense and mutually supportive intra-cluster relationships and a glaring absence of cooperation. Even though some occupants believe that the cluster can have value, with joint exhibitions and sharing of ideas, in reality, this does not happen. In short, there is no causal relationship between geographical propinquity and the development of positive social relations. Indeed, the close proximity puts strains on relationships, which might not be as immediate or as apparent if it were not for co-location. Nevertheless, the cluster continues to exist and to enjoy its status as an important site for the practice of visual arts in Singapore. This is because of the reputational effect that occupants of the cluster enjoy, drawn from the concentrated location of a significant number of award-winning artists, offering all occupants some much-valued cultural capital. The environment being quiet and one of isolation also allows artists to give expression to their 'individual genius'. Importantly, the subsidized rents of this NAC arts housing facility make co-location a prudent decision. By comparison, the much newer Old School found its new lease of life in 2007 as a complex of heritage buildings housing art galleries, artist studios, an art film theatre, design firms, photographers, musicians and others. A group of three entrepreneurs with an interest in the arts got together and successfully secured the lease from the Singapore Land Authority, with a plan to turn the former school site into a creative hub and to promote 'madein-Singapore creativity' to the world. With over 30 tenants, the intention was to showcase interesting art forms and provide a place for exchange and stimulation, curation and interaction. The initiative thrived, but the lease ran out as the government turned the land over to private developers for residential development.

The preceding academic 'travel' through the cultural landscapes of the five Asian cities culminates in the final chapter, where we step back from the rich and detailed ethnographic and textual material for each city and the grounded analysis of individual contexts to draw broader conclusions about culture, urban landscapes and global cities. It is our hope that this book addresses the shortage of micro-level analyses of creative or cultural worlds at ground level, and uses this empirical analysis to draw on larger theoretical canvases. 


\section{NOTES}

1. Friedmann (1995, p. 31) uses the terms 'global cities' and 'world cities' interchangeably.

2. Core countries were identified using World Bank criteria, and included 19 industrial market economies. Semi-peripheral countries mostly included upper-middle income countries with a significant degree of industrialization and an economic system based on market exchange.

3. The word billion is used throughout this book in its US sense, meaning 'one thousand million'.

4. We use the terms cultural industries, creative industries and cultural creative industries (and their derivatives, for example, cultural/creative clusters) interchangeably here; they are related, yet not the same. Studies stemming from Europe (with the exception of the United Kingdom) commonly use the term cultural clusters while those from the United States and Australia appear to favour the term creative clusters. Often, this proliferation of terms reflects the lack of conceptual clarity around the ideas of 'cultural industries' and 'creative industries' themselves. It is not our intention in this book to work through the differences, though we recognize that they are not inconsequential. We recognize that, at a fairly broad level of generalization, the phenomenon that we are interested in does not suffer from the interchangeable use of the terms. 